\title{
Developing student writing in science and engineering: the Write Reports in Science and Engineering (WRiSE) project
}

\author{
Helen Drury \\ University of Sydney, Australia
}

Pam Mort

University of New South Wales, Australia

\begin{abstract}
This paper reports on the design, development, implementation and evaluation of a discipline-specific online report writing resource for undergraduate science and engineering students, known as 'Write Reports in Science and Engineering' (WRiSE). WRiSE was developed by a cross-institutional and cross-discipline collaborative team made up of subject specialists, learning advisors and eLearning specialists. Its conceptual design is based on research and pedagogy in 'Learning to Write' and 'Writing to Learn'. Genre analysis and genre pedagogy in the Sydney School tradition underpin the 'Learning to Write' resources. WRiSE contains nine modules from eight disciplines. Each module brings together resources to support student learning of both report writing and discipline content relevant to reporting experimental or field work. The site addresses student learning about the product of writing, namely the report genre, as well as the writing process. Evaluations post-project have shown that WRiSE users attained higher marks than non-users in their report assignments. Users also rated WRiSE highly for: developing understanding of the report writing requirements in their discipline; increasing awareness of strengths and weaknesses in their report writing; and, for deciding what changes to make to their report. WRiSE works best when integrated into the curriculum and when it is regularly promoted and demonstrated by lecturers, tutors and learning advisors.
\end{abstract}

Keywords: engineering education; genre pedagogy; online learning; report writing; science education. 


\section{Introduction and background}

In Australia, as in the UK, there have been ongoing concerns about the writing skills of students studying in science and engineering disciplines. Both employers and government have frequently referred to graduates who do not possess the necessary communication skills for professional practice (Department of Education, Science and Training (DEST), 2007; Accreditation Board for Education and Technology (ABET), 2011). Although this issue is not new (AC Nielson Research Services, 2000), it has been compounded in recent years by an increasingly diverse student population. Commencing students in science and engineering vary in terms of language and cultural background as well as prior educational experience which may mean that they have had little practice in extended writing. This situation is exacerbated by other factors, namely a curriculum where writing is seen as a low priority and faculty staff who feel challenged to teach writing in their discipline, articulate how they assess student writing or address issues of plagiarism and feedback.

Collaborative approaches to address these issues have been pursued over the last ten years between discipline staff and staff with expertise in language and learning at the Universities of Sydney and New South Wales. This has resulted in a number of learning programs for writing development, both paper based and online as well as research initiatives to analyse the writing tasks or genres of the science and engineering disciplines (see for example, Drury et al., 2006; Skinner and Mort, 2009). Despite the success of these programs, the insights gained about the writing process and the writing product have mostly remained within the particular unit of study and with the particular discipline staff member. This means that these programs cannot support the transitions students need to make in their written communication of disciplinary knowledge as they move through the undergraduate years. Furthermore, students need to understand the similarities and differences in written communication within and across disciplinary boundaries. Clearly a more systematic co-ordinated and comprehensive approach was needed to provide more effective development of students' writing. The opportunity for such an approach arose with the advent of the Australian Learning and Teaching Council (ALTC), a Commonwealth Government funded institution to support teaching and learning developments in higher education (now known as the Office for Learning and Teaching (OLT) located within the Department for Education, Employment and Workplace Relations - http://www.deewr.gov.au/HigherEducation/Programs/Quality/Pages/OLT.aspx). A successful grant from the ALTC supported the creation of an 'integrated student-centred 
online learning environment for report writing in the sciences and engineering' now known as WRiSE (Write reports in science and engineering http://learningcentre.usyd.edu.au/wrise/).

This paper will report on the WRiSE project. It will discuss the choice of an online discipline-based approach and the focus on the report genre and then elaborate the principles and theory underpinning the design. Further sections will report on the development, implementation and evaluation of WRiSE. The discussion will highlight the challenges experienced and ongoing issues.

\section{Online learning and the report genre}

The advantages of online learning in the area of flexibility and accessibility, especially in asynchronous online formats, have been widely acknowledged (see for example, Cole, 2000; Hiltz and Shea, 2005; Hirschheim, 2005; Goodyear, 2006; Ally, 2008; Daymont et al., 2011). However, there is ongoing debate on the learning outcomes achieved and their evaluation (Alexander, 2001; Swan, 2003; Thompson, 2004; Reeves et al., 2005; Means et al., 2009) Students can access online learning resources in a self-paced manner and create their own learning pathway through the materials. An online environment also provides multiple modes of learning to engage students in different ways. This approach is also a way to overcome the challenge of embedding face-to face learning activities to address writing in crowded science and engineering curricula. However, there are constraints in an online environment, as students have to monitor their own learning with only the computer as teacher. In particular, when teaching writing, computer feedback alone is limited. Therefore, WRiSE is not only a resource for individual self-paced learning but also one which can be used for blended learning in face-to-face interactions in lectures and tutorial and lab sessions.

Although there have been a number of successful approaches to teaching writing online, many of them focus on the generic aspects of a report or essay genre (see for example, http://www.writing.engr.psu.edu/) and may also be fairly limited in the degree of interactivity they include in the design (see for example https://academicskills.anu.edu.au/resources/listing/114). WRiSE is a unique resource providing a discipline-specific online learning environment across eight discipline areas 
and from year one to three of the undergraduate degree program (Figure 1). It presents the report genres in the way that students experience these as they move across discipline boundaries in their degree program. It combines information on both the product and process of report writing as well as the discipline content of reports students are writing. In this way it aims to overcome the separation of language choices from the communication of discipline knowledge.

Figure 1. Home page of the WRiSE site.

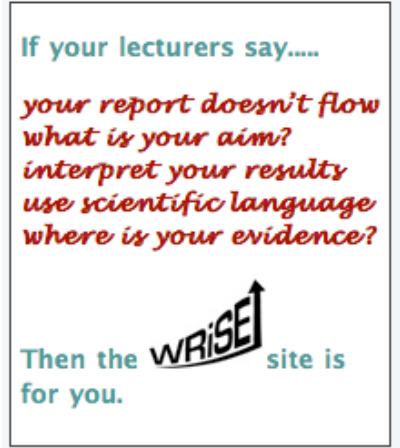

Guide for Students

Guide for Staff

Site Map

Help \& Troubleshooting

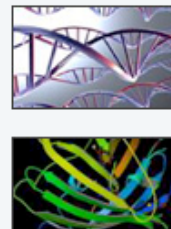

Molecular

Biology - Yr 2

Molecular

Biology - Yr 3

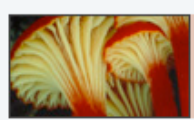

Biology

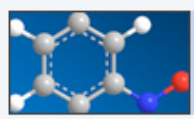

Chemistry

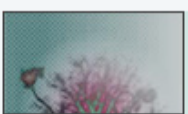

Physiology

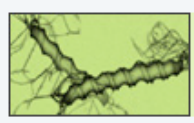

Microbiology
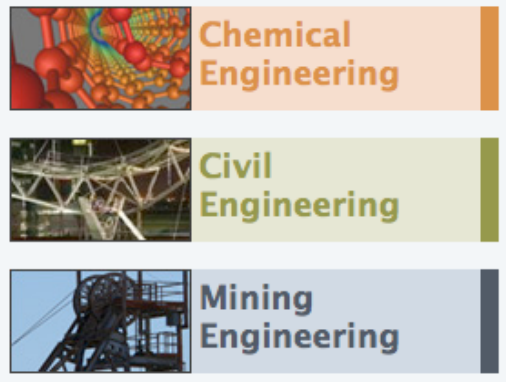

This focus on the report genre in WRiSE was partly because a repository of effective materials already existed in this area but also because the report genre, whether based on laboratory or fieldwork, is one of the most commonly assessed writing tasks in the sciences and engineering throughout the undergraduate years. This means that it is a highly relevant genre for students to learn and differentiate across disciplines. Also students struggle with report writing, especially in interpreting and commenting on their results and developing an argument in the discussion section. However, students also struggle with the concepts behind the reports they are required to write and often do not understand the purpose of documenting their experimental or field findings in
Figure 2. Chemical Engineering entry screen. 
a report. For this reason, each discipline module in WRiSE brings together learning materials not only to support report writing (Help with Report Writing) but also to support understanding of the content behind reports or to understand general concepts connected with experimental work in the discipline (Help with Understanding Content) (Figure 2). Providing support for understanding the content of assessment tasks is an incentive for students to access WRiSE and engage with the learning materials.

\section{Design principles}

Although designing learning resources to motivate and engage students is critical in all teaching situations, it is particularly important in online learning where students are largely free to use the learning environment as they choose. Our aim was to create a rich resource with relevant and realistic materials which would encourage students to reflect on both the writing process and product. These three principles - rich, relevant and realistic are the ' 3 Rs' of the WRiSE design which together support a fourth, a reflective approach to writing.

WRiSE is a rich resource which uses multimodal and interactive elements to present explanations, examples and exercises on writing from a number of perspectives. It includes a range of authentic examples of discipline-based reports, a frequent request in student feedback. However, these are realistic examples for student writers to aim for since they have been drawn from a corpus of student report writing rather than the writing of experts in the disciplines, for example, 'Example reports showing what to do and what not to do were most helpful' (student comment, WRiSE questionnaire, 2009). Since the report examples are discipline based they are also relevant to the kinds of discipline knowledge students are engaging with. In addition, each discipline module brings together resources to help students with understanding both writing and content, once again making it highly relevant for students to engage with.

It's good it uses chem eng content as gives practical examples of what we have to write. (student comment, WRiSE questionnaire, 2009) 
The WRiSE interface presents learning resources in a structured and coherent way. Figure 3. Menu design. Each module is identified through a distinctive colour and visual which is continued throughout the module so that students know immediately where they are in the site and can easily make comparisons among disciplines (see Figure 1). In addition, the menu items within the Help with Report Writing modules follow the logical structure of a report, thus reinforcing the macro structure of the genre that students are required

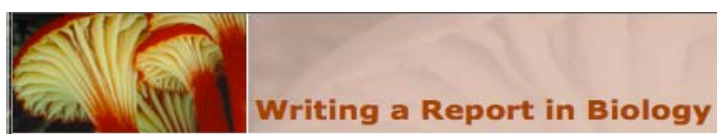

Title Introduction Methods

Results

Discussion References Example Report to write. Sub menu items guide students to explore the structure and language features of each section of a report. This approach is repeated in each discipline module giving coherence to the whole site (Figure 3).

The multimodal possibilities of the Figure 4. Discussion Structure. computer are used to make the structure and language features of the example reports explicit. For example, graphics, colour and animation are used to reveal the structure of each section of a report and the stages in the structure are linked to report examples (Figure 4). Students can check their understanding through a range of interactive exercises, such as multiple choice or drag and drop and receive immediate feedback.

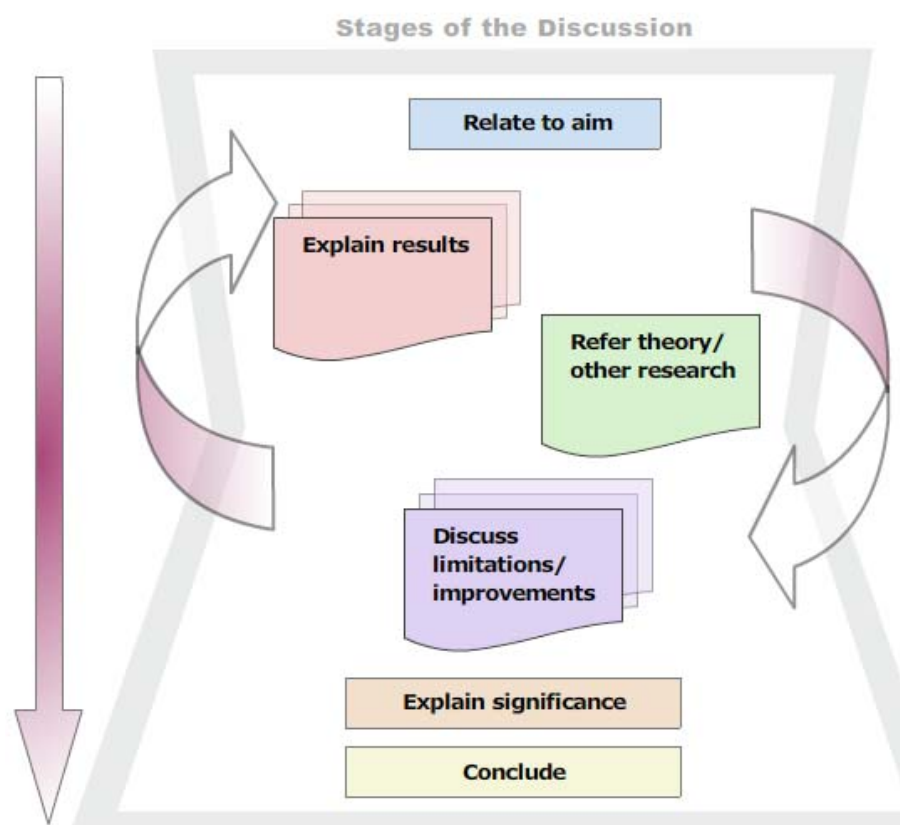


It had a sample introduction and then it had a highlighted each component of each part of the introduction that you needed, which was really good.

Seeing those different colours is what helped me the most and, yep, I did change it. I wrote mine and then went to this site and looked at it and then went back and changed it. (student comments WRiSE questionnaire, 2009)

As well as deconstructing the report as a text product, WRiSE also helps students learn about the process of report writing and the expectations of lecturers through audio recordings of student and staff interviews. Students talk about how they went about writing their report and the challenges they experienced and how they overcame these, while discipline staff talk about their expectations of student writing and the typical problems students experience.

Good to hear from people we knew, more real. (student comment, WRiSE questionnaire, 2009)

\section{Theoretical underpinnings}

The design and development of WRiSE is influenced by research and pedagogy in 'Learning to Write' and 'Writing to Learn' (for discussions about these approaches and their interrelationships at tertiary level, see for example, Ackerman, 1993; McLeod et al., 2001; Carter, 2007; Carter et al., 2007). The resources in WRiSE which support students 'Learning to Write' in the disciplines are based on genre analysis and genre-based pedagogy. These applied linguistic approaches draw on a number of traditions (for example, Swales, 1990; Bhatia, 1993; Berkenkotter and Huckin, 1995; Hyland, 2003) but the main tradition used in WRiSE is the Sydney School approach to genre and genre pedagogy (Martin, 1999; Martin and Rose, 2008). In this tradition, the choice of structures and language in report genres become meaningful in terms of their social context and purpose, the discipline culture they are embedded in and the communication act they fulfil. Genre pedagogy aims to make genres and their social purpose explicit to students through a teaching/learning cycle where structure and language in example texts are first deconstructed in the context of their field. Then students are apprenticed through writing practice and feedback into the genres of their disciplines, a 'genre-based literacy 
pedagogy' (Martin and Rose, 2008). This approach to teaching academic writing is well established in both face-to-face and online learning environments (Drury, 2004; Jones, 2004). In the WRiSE environment, students can choose their own teaching/learning cycle depending on their needs; they can check their initial understandings of the structure and language of each section of a report genre though an entry quiz and then engage with examples and exercises to improve their understanding. In a blended approach, lecturers can scaffold report assignments by referring students to different parts of WRiSE to prepare their draft reports and also use WRiSE in the feedback process by recommending students to use specific sections of WRiSE to improve their performance.

'Writing to learn' approaches, although generally acknowledged to be more generic and informal approaches to writing development, also occur in the context of students' studying in the disciplines and contribute to their mastery of the formal genres of the discipline (McLeod and Maimon, 2000; Petrucci, 2002). These approaches also help students build their knowledge in the discipline and support deep learning, reflection and critical thinking (Scardamalia and Bereiter, 2006). This approach is seen in Writing Across the Curriculum (WAC) pedagogy, especially in science and engineering education (Jones, 2004; Reynolds et al., 2012). WRiSE aims to develop students' understanding of disciplinary concepts and knowledge and how these are expressed in language through the cooccurrence of the Help with Report Writing and Help with Understanding Content modules. In addition, WRiSE contains report genres from different disciplines and across different degree stages, and in this way, students can more easily make comparisons across the discipline boundaries in which they are studying and gain insights into how the communication of knowledge varies. In this way, WRiSE supports a 'Writing to learn' approach where students can become more aware of disciplinary differences and adopt a more metacognitive approach to the writing process and product.

Both 'Learning to Write' and 'Writing to Learn' approaches need to be informed by students' experiences of learning such as their prior learning, their motivation and their current perceptions of and approaches to virtual teaching and learning experiences (Prosser and Trigwell, 1999; Ellis and Goodyear, 2010). The 'conversational framework' approach (Laurillard, 2002) has influenced the design of the report modules as it begins with prior student understandings and through 'dialogue' (computer/student interaction) shifts students' understandings towards shared concepts of subject matter. 


\section{Development}

Since the project encompassed eight disciplines, ranging across two institutions and involved the staff of two Learning Centres and an eLearning Centre, it was essential to build a team approach for the success of this project. Team members brought expertise in their disciplines and most importantly insights into how writing is used to convey disciplinary knowledge. Language and learning specialists were able to analyse the genres of the different reports across the disciplines and eLearning specialists brought their knowledge of online learning to the design of the site. This collaborative approach created a community of practice around academic writing in science and engineering as a basis for beginning to map the genres of the undergraduate years across these disciplines.

The development of WRiSE continued over an 18-month period, including staged trialling and feedback. During this time, a corpus of student writing in each new discipline area was collected and examples chosen as the basis for the development of learning materials. These examples were analysed for generic structure and language and used to develop the explanations and exercises in the Help with Understanding Report Writing part of the site. At the same time, the earlier report writing materials were redesigned and integrated into the site so that a coherent approach to design was achieved. Discipline staff attended workshops on using Question Tools software to develop materials for the Help with Understanding Content part of the site. The materials for report writing were circulated to discipline staff for feedback and comments before the next stage of development into online materials. Audio recordings were made with staff and student and extracts integrated into the site at appropriate places. Overall this process comprised a spiral/feedback approach to design and development with designated milestones to be achieved along the way to ensure the delivery of the project.

\section{Implementation and evaluation}

WRiSE was implemented and extensively evaluated in 2009. Implementation activities varied across the disciplines. In some cases, students were introduced to the site via lectures and in others during lab sessions or tutorials. If time allowed, students would work in pairs on part of a relevant module and engage in exercises. However for the most part, the site was displayed either by faculty or language and learning specialists in lecture time. 
The evaluations consisted of software tracking of site usage, questionnaires and focus groups/interviews with both students and staff. Student report marks were also recorded and comparisons made between users $(n=242)$ and non-users $(n=175)$ of the site. Ongoing evaluation is currently carried out via software tracking. In semester 1, 2009, approximately 1000 unique visitors used the site during the implementation period (about half of the targeted cohort). More recent tracking data over the same period in 2011 has shown a doubling of site usage in terms of new visitors as well as a wider national and international site usage and this trend has continued into 2012.

During implementation in 2009, evaluation questionnaires were distributed to a random sample of tutorial groups across seven of the discipline areas. The survey was conducted after students had submitted their report but before it had been assessed. Approximately 500 students (about $25 \%$ of the cohort) were invited to complete the questionnaires. Overall, the response $(n=417)$ confirmed the usefulness of WRiSE by users $(n=242)$. The majority of non-users $(n=175)$ reported that they did not know about the site, despite the fact that it was strongly promoted in lectures and tutorials. Student users rated WRiSE highly, reporting improved understanding of the structure and language of reports through their interactions with the site and increased confidence in their report writing skills. In addition, their understanding of content in their discipline improved as well as their confidence in knowing what content to put in their report. A summary of the questionnaire data is presented in Figure 5. The data consists of the average of students' level of agreement with 13 statements on how aspects of the modules improved their understanding. Ratings were based on a Likert scale that ranged from strongly agree to strongly disagree with the statements. 
Figure 5. The average of respondents' ( $n=242)$ overall rating of their improved understanding from interacting with various aspects of the WRiSE modules where ratings range from strongly agree to strongly disagree.

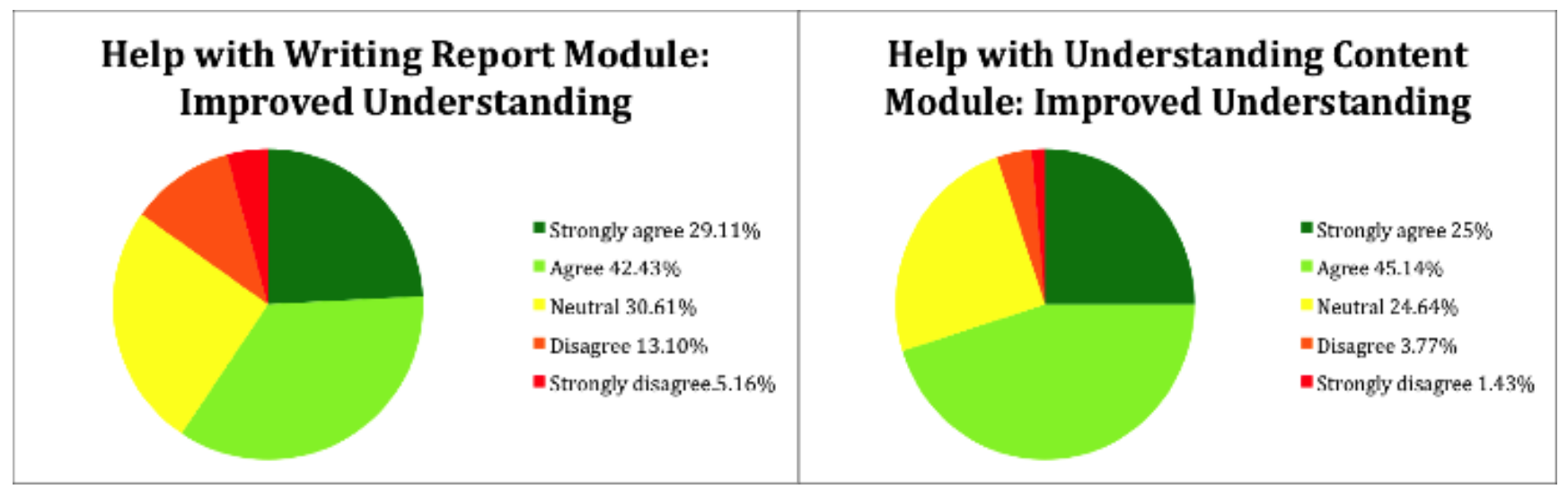

Open-ended comments from the student questionnaires and focus group data $(n=4 \times 5$ students per group) supported these findings. Example extracts are included below:

WRiSE helped me to think more clearly and concisely about what a scientific report should be like.

WRiSE gave me the basic structure of what reports are accepted at uni as opposed to high school.

The things I wrote were more relevant, more succinct and less junk.

In terms of performance, we were able to conclude that WRiSE did make a difference to students' report marks. In general, users gained better marks than non-users, and when marks were pooled across disciplines, the report marks of those who used the website ( $M$ $=0.13, \mathrm{SD}=0.97, \mathrm{n}=204$ ) were significantly higher than those who did not use the website $(M=-0.19, S D=0.98, n=144 ; t(306)=-3.02, p=0.01)$. That is, those who used the website scored, on average, 0.13 standard deviations above the mean for all students while those who did not use the website scored, on average, 0.19 standard deviations below the mean for all students. Thus interacting with WRiSE positively influenced report marks across disciplines and this remained the case even when controlling for the greater experience of writing reported by the user group. 
Discipline staff $(n=14)$ who were involved in the project were also invited to provide feedback through open-ended responses on an anonymous questionnaire. Those who responded $(n=4)$ reported improvements in student writing and positive experiences of being involved in the project. Some examples of responses are shown below:

...strongly encouraged to use the site. Quite an improvement. I feel we definitely have a well-designed pedagogically sound website. New working relationships and collaborative links with colleagues across the university.

WRiSE is a freely available resource and software tracking has shown the ongoing use of the site. Lecturing and tutoring staff in the disciplines are committed to promoting WRiSE as they can experience the benefits in terms of a reduced marking burden. Although new students at both universities have reported how helpful the site has been in developing their report writing, many continue to request resources to help them with specific report assignments. Thus, even a discipline-specific site like WRiSE seems to pose a challenge for students to transfer what they have learned to new report writing contexts. Tracking data shows that, as expected, most visitors come from within Australia. However a substantial proportion come from other countries (30\% in 2011 with approximately 20,000 visitors in total to the site up to December 2011) and we have received positive commendations via email correspondence from Europe, Latin America and Japan, such as:

We are two lecturers at Chalmers University of Technology (Goteborg) who work at the Centre for Language and Communication. We are in the process of designing an OWL for our students (mainly engineering students) to help them with their writing of reports. We are very impressed by your website and have recommended it for many of our students! (unsolicited email 31 March 2011)

\section{Conclusion: challenges and issues}

The ongoing sustainability of an online learning environment for the development of written communication is critically dependent on discipline staff promoting and using it as part of their curriculum. This means that the laboratory or field activities as well as other curriculum content is aligned with the written assignments and the online resources that 
scaffold this writing. WRiSE is one example of how students can be supported in the development of their report writing. WRiSE helps students to deconstruct the product and process of writing across disciplines in science and engineering, and furthers their understanding of how language is used to communicate discipline knowledge. However, only in a blended approach can this kind of environment be used to foster the social aspects of learning in face-to-face interactions. Online social elements could also be added through discussion boards and blogs as well as through peer feedback and group writing. These activities offer the opportunity for further collaborations among discipline staff and language and learning specialists and the opportunity for an ongoing community of practice for writing development in science and engineering.

\section{References}

AC Nielson Research Services (2000) Employer satisfaction with graduate skills: research report. Commonwealth of Australia: Evaluations and Investigations Programme, Higher Education Division.

Accreditation Board for Education and Technology (ABET) (2011) Criteria for Accrediting Engineering Programs, 2011-2012. Available at: http://www.abet.org/ (Accessed: 27 April 2012).

Ackerman, J.M. (1993) 'The promise of writing to learn', Written Communication, 10(3), pp. 344-370.

Alexander, S. (2001) 'E-learning developments and experiences', Education and Training, 43(4), pp. $240-248$.

Ally, M. (2008) 'Foundations of educational theory for online learning', in Anderson, T. (ed.) The theory and practice of online learning. $2^{\text {nd }}$ edn. Athabasca University: Athabasca University Press, pp.15-44.

Berkenkotter, C. and Huckin, T. (1995) Genre knowledge in disciplinary communities. Mahwah, NJ: Lawrence Erlbaum. 
Bhatia, V.J. (1993) Analysing genre. London: Longman.

Carter, M. (2007) 'Ways of knowing, doing and writing in the disciplines', College Composition and Communication, 58(3), pp. 385-418

Carter, M., Ferzli, M. and Wiebe, E. (2007) 'Writing to learn by learning to write in the disciplines', Journal of Business and Technical Communication, 21(3), pp. 278-302.

Cole, R.A. (ed.) (2000) Issues in web-based pedagogy: a critical primer. Westport, Conn: Greenwood Press.

Daymont, T., Blau, G. and Campbell, D. (2011) 'Deciding between traditional and online formats: exploring the role of learning advantages, flexibility, and compensatory adaptation', Journal of Behavioral and Applied Management, 12(2), pp.156-175.

Department of Education, Science and Training (DEST) (2007) Graduate employability skills Final Report Prepared for Business, Industry and Higher Education Collaboration Council Precision consultancy. Available at: http://www.dest.gov.au/highered/bihecc (Accessed: 27 April 2012).

Drury H. (2004) 'Teaching academic writing on-screen: a search for best practice', in Ravelli, L. and Ellis, R. (eds.) Analysing academic writing: contextualised frameworks. London: Continuum, pp. 233-253.

Drury, H., Langrish, T. and O'Carroll, P. (2006) 'Online approach to teaching report writing in chemical engineering: implementation and evaluation', International Journal of Engineering Education, 22(4), pp. 858-867.

Ellis, R. and Goodyear, P. (2010) Students' experiences of e-learning in higher education: the ecology of sustainable innovation. New York and London: Routledge.

Goodyear, P. (2006) 'Technology and the articulation of vocational and academic interests: reflections on time, space and e-learning', Studies in Continuing Education, 28(2), pp. 83-98. 
Hiltz, S.R and Shea, P. (2005) 'The student in the online classroom', in Hiltz, S.R. and Goldman, R. (eds.) Learning together online: research on asynchronous learning networks. Mahwah, NJ: Lawrence Erlbaum Associates, pp. 145-168.

Hirschheim, R. (2005) 'The internet-based education bandwagon: look before you leap', Communications of the ACM, 48 (7), pp. 97-101.

Hyland, K. (2003) 'Genre-based pedagogies: a social response to process', Journal of Second Language Writing, 12(1), pp.17-29.

Jones, J. (2004) 'Learning to write in the disciplines: the application of systemic functional linguistic theory to the teaching and research of student writing', in Ravelli, L. and Ellis, R. (eds.) Analysing academic writing: contextualised frameworks. London: Continuum, pp. 254-273.

Laurillard, D. (2002) Rethinking university teaching. $2^{\text {nd }}$ edn. London and New York: Routledge/Falmer.

Martin, J. R. (1999) 'Mentoring semogenesis: 'genre-based' literacy pedagogy', in Christie, F. (ed.) Pedagogy and the shaping of consciousness: linguistic and social processes. London: Cassell, pp. 123-155.

Martin, J.R. and Rose, D. (2008) Genre relations: mapping culture. Equinox: London.

McLeod, S. and Maimon, E. (2000) 'Clearing the air: WAC myths and realities', College English, 62(5), pp. 573-583.

McLeod, S.H., Miraglia, E., Soven M. and Thaiss, C. (2001) WAC for the new millennium: strategies for continuing writing-across-the curriculum programs. Urbana, IL: National Council of teachers of English. 
Means, B., Toyama, Y., Murphy, R., Bakia, M. and Jones, K. (2009) 'Evaluation of evidence-based practices in online learning: a meta-analysis and review of online learning studies', U.S. Department of Education Office of Planning, Evaluation, and Policy Development, Policy and Program Studies Service. Available at: http://www2.ed.gov/rschstat/eval/tech/evidence-based-practices/finalreport.pdf (Accessed: 18 September 2012).

Petrucci, P. (2002) 'A writing to learn approach to writing in the discipline in the introductory linguistics classroom', The WAC Journal, 13, pp.133-143.

Prosser, M. and Trigwell, K. (1999) Understanding learning and teaching. Buckingham: SRHE and Open University Press.

Reeves, T., Herrington, J. and Oliver, R. (2005) 'Design research: a socially responsible approach to instructional technology research in higher education', Journal of Computing in Higher Education, 16(2), pp. 96-115.

Reynolds, J., Thaiss, C., Katkin, W. and Thompson, Jr. R.J. (2012) 'Writing-to-learn in undergraduate science education: a community-based, conceptually driven approach', CBE-Life Sciences Education 11(1), pp. 17-25.

Scardamalia M. and Bereiter C. (2006) 'Knowledge building: theory, pedagogy, and technology', in Sawyer, K. (ed.) Cambridge handbook of the learning sciences. New York: Cambridge University Press, pp. 97-118.

Skinner, I. and Mort, P. (2009) 'Embedding academic literacy support within the electrical engineering curriculum: a case study', IEEE Transactions on Education, 52(4), pp. 547-554.

Swales, J. (1990) Genre analysis. Cambridge: Cambridge University Press.

Swan, K. (2003) 'Learning effectiveness: what the research tells us', in Bourne, J. and Moore, J.C. (eds.) Elements of quality online education, practice and direction. Needham, MA: Sloan Center for Online Education, pp.13-45. 
Thompson, M. (2004) 'Evaluating online courses and programs', Journal of Computing in Higher Education, 15(2), pp. 63-84.

\section{Author details}

Ms Helen Drury is a senior lecturer and Head of the Learning Centre, the University of Sydney. She has worked in the area of academic literacy and learning for more than 20 years in Australia, the UK and Indonesia. She has developed and taught generic programs in academic literacy and worked collaboratively to integrate academic literacy into subject area curricula. She has been manager and project leader on two Australian Government award-winning projects to develop discipline specific online programs for supporting students in writing scientific and engineering genres. She has published and presented widely in the areas of scientific and technical writing, genre analysis and online learning of academic literacy.

Ms Pamela Mort is an experienced Learning Advisor at the Learning Centre, University of South Wales (UNSW). She has collaborated with the Faculties of Science and Engineering at UNSW for the past 14 years to develop courses, diagnostic tools and resources to improve the learning and communication skills of students. Her work has been recognised institutionally and nationally. Since 2009 Pam has been a project member on two Australian Government funded cross-institutional projects to develop online resources for technical writing. Her research interests include genre pedagogy, Systemic Functional Grammar, and writing across the curriculum. 